Check for updates

, London, UK

Correspondence to: T Richards trichards@bmj.com Cite this as: BMJ2020;370:m2575 http://dx.doi.org/10.1136/bmj.m2575 Published: 01 July 2020

\section{Patient and public involvement in covid-19 policy making}

\author{
Absent in the early stages of the pandemic, it must now move centre stage \\ Tessa Richards, Henry Scowcroft
}

The covid-19 pandemic saw statutory policy commitments to patient and public involvement and shared decision making in health systems abandoned, the "nothing about us without us" mantra left hanging in the breeze.

Decisions had to be made fast, but policy makers' choice of expert advisers excluded those with expertise rooted in lived experience-patients, families, and frontline health and social care professionals. This was regrettable. Their input would have helped to mitigate the predictable adverse effects of massive service reconfiguration and lockdown, and emphasised the need for clarity on which services would be suspended and which would remain accessible.

These steps would have reduced the anxiety, helplessness, and reticence to use services that followed. It might have prevented at least some of the excess morbidity and mortality associated with pandemic responses, particularly among elderly people, those with long term conditions, and those in lower socioeconomic groups. ${ }^{12}$

Patient and civil society advocacy groups may have lacked seats on expert committees but took the lead in providing information, advice, and support for their communities. ${ }^{3}$ They have lobbied for a voice in policy making, ${ }^{4}$ for a focus on inequalities, ${ }^{5}$ and for policies to take account of the reality of people's lives. ${ }^{6}$ They have also accumulated a wealth of information from the patient community on the physical, mental, social, and economic effects of the pandemic, ${ }^{78}$ effects that highlight the urgency of restoring essential medical services ${ }^{9}$ and the need for a comprehensive public health response. ${ }^{10}$

\section{Embedding the patient voice}

The precipitate loss of civil liberties and continued uncertainty around the efficacy of policies that profoundly affect how people live and work, have eroded trust and prompt searching questions.

Firstly, why were the voices of patients and the public tuned out? Despite decades of activism, public and patient involvement is still largely seen as "nice to have" but non-essential-a second step to be carried out after an initial round of consultation with academic, clinical, public health, and policy experts. The resources, skills, views, priorities, and preferences of patients, carers, and the communities which support them are not well recognised, valued, or systematically used to improve care. Early in the pandemic, the priority was to protect the health workforce. ${ }^{11}$

Secondly, how could health leaders do better now? Patient advocates, organisations, and civil society clinic to the conference floor. networks are primed to inform joint learning from the pandemic and help shape post-covid services and research agenda. ${ }^{12-14}$ New collaborations are underway, including in cancer care ${ }^{15}$ and ophthalmology. ${ }^{16}$ More are needed. Regrettably, the explosion of research into covid-19 has been associated with a drop in public and patient involvement, ${ }^{17}$ but a joint initiative to agree core outcomes has been launched (https://www.covid-19cos.org/).

Thirdly, how can we ensure that patient and public involvement becomes irreversibly embedded in decision making? This is more challenging.

Approaches vary and most are flawed. The voluntary advisory groups attached to general practices and hospital departments in the UK (whose work was immediately suspended at the pandemic's onset) are largely unrepresentative and too often used to "rubber stamp" policy decided elsewhere. Industrial quantities of patient experience data are rarely used as a catalyst for quality improvement. ${ }^{18}$ Co-design of services is still uncommon and co-production of research not widely achieved. Patients' role in defining value in health systems remains weak.

New approaches are needed that capitalise on online communication-now the norm for patient and civil society groups. Input from under-represented groups is not hard to achieve, if the will is there and digital divides addressed. ${ }^{19}$ More collaborative platforms should be established to unite patient communities with professional groups, informed by successful existing models (https://www.parkinsonnet.com/). ${ }^{20}$ International initiatives such as Patients for Patients Safety need to be strengthened and more interactive platforms developed to facilitate exchange, from the

Mutual understanding and respect is essential in any partnership, and patient leadership must be taken seriously by both health professionals and patients. Experienced advocates should be appointed to advance shared decision making at strategic levels in the health sector. The UK has only a handful of paid patient directors, for example. More and better training programmes in patient leadership are required for managers, clinicians, ${ }^{21}$ patients, and carers, ${ }^{22}$ along with wider uptake up of joint care models in which patients and carers are integrated into multidisciplinary teams in both primary and secondary care. ${ }^{2324}$ Collectively, these steps will help change health care culture and counter what Montori describes as a "corruption in the mission" of health systems. ${ }^{25}$

Finally, providing people with full online access to personal health records and test results, will improve the quality and safety of care, and raise health literacy 
on both sides of the professional fence. This is essential as remote services increase and people take on a larger role in self-monitoring and self-management. Patient and public involvement should be routine in medical education, with health professionals taught and appraised in partnership skills. ${ }^{26}$

Covid-19 has precipitated a global health crisis, plunged the world into economic recession, put the spotlight on structural inequalities, including racism, and galvanised the call for action on climate change. The knowledge to confront these challenges needs to be co-produced. ${ }^{27}$ Patient and public involvement must be taken seriously, embedded robustly, and never sidelined again.

The BM/s collection of Patient and Public Perspectives on the pandemic can be found here: https://blogs.bmj.com/bmi/category/patient-perspectives/

Competing interests: We have read and understood BMJ policy on declaration of interests and declare the following interests: TR lives with adrenal cancer and other long term conditions. HS is communications strategy manager at Cancer Research UK.

Provenance and peer review: Commissioned; not externally peer reviewed.

The members of The BM/s patient and public advisory panel can be found here

(https://www.bmj.com/about-bmj/advisory-panels/patient-panel-members). We thank David Gilbert, patient director, Sussex MSK Partnership (Central), who contributed to the section on patient leadership

1 Eurohealthnet. What covid-19 is teaching us about inequality and the sustainability of our health systems. 2020 https://eurohealthnet.eu/COVID-19

2 Office for National Statistics. Deaths involving Covid-19 by local area and socioeconomic deprivation: deaths occurring between 1 March and 31 May 2020. 16 June 2020 https://www.ons.gov.uk/peoplepopulationandcommunity/birthsdeathsandmarriages/deaths/bulletins/deathsinvolvingcovid19bylocalareasanddeprivation/deathsoccurringbetween1marchand31may2020

3 Richards T. The toll beyond the covid-19 deaths. BMJ Opinion, 14 Apr 2020. https://blogs.bmj.com/bmi/2020/04/14/tessa-richards-the-toll-beyond-the-covid-19-deaths/

4 Immonen $\mathrm{K}$. The views of patients and the public should be included in policy responses to covid-19. BMJ Opinion, 30 Mar 2020. https://blogs.bmj.com/bmj/2020/03/30/the-views-of-patients-and-the-public-should-be-included-in-policy-responses-to-covid-19/

5 National Voices. Submission to the Health and Social Care Select Committee inquiry on "delivering core NHS and care services during the pandemic and beyond." 2020. https://www.nationalvoices.org.uk/publications/our-publications/submission-health-and-social-care-select-committee-inquiry-\%E2\%80\%98delivering

6 Augst C. Let's get the evidence on shielding out in the open and start conversation about how people want to live. BMJ Opinion, 3 Jun 2020. https://blogs.bmj.com/bmj/2020/06/03/lets-getthe-evidence-on-shielding-out-in-the-open-and-start-a-grown-up-conversation-about-howpeople-want-to-live/

7 International Alliance of Patient Organisations. COVID-19 response activities by IAPO members and partners. 20209 June. https://www.iapo.org.uk/covid-19-response-activities-iapo-membersand-partners

8 National Voices. Our covid voices. 2020 https://ourcovidvoices.co.uk/

9 Marquez PV. Sustaining essential health services during the covid-19 pandemic: a social imperative. 2020 June 15 http://pvmarquez.com/essentialhealthservices

10 Prasad V, Sri BS, Gaitonde R. Bridging a false dichotomy in the COVID-19 response: a public health approach to the 'lockdown' debate. BMJ Glob Health 2020;5: doi: 10.1136/bmjgh-2020-002909 pmid: 32527850

11 Drinkwater J. Back to the future? Patient participation in general practice during covid-19. BMJ Opinion, 4 June 2020. https://blogs.bmj.com/bmi/2020/06/04/jessica-drinkwater-back-to-thefuture-patient-participation-in-general-practice-during-covid-19/

12 Redding D. Service "reset" must be informed by patients' experience of the covid-19 pandemic. BMJ Opinion, 21 May 2020. https://blogs.bmj.com/bmj/2020/05/21/don-redding-service-resetmust-be-informed-by-patients-experience-of-the-covid-19-pandemic/

13 Giles C, Crowe S. Making remote consultations work for patients during covid-19: experience from the "other side" of the virtual clinic. BMJ Opinion, 21 May 2020.

https://blogs.bmj.com/bmj/2020/05/21/making-remote-consultations-work-for-patients-duringcovid-19-experience-from-the-other-side-of-the-virtual-clinic/

14 Fitzsimons B. We mustn't silence patients and families in service design. Point of Care Foundation blog, 17 Jun 2020. https://www.pointofcarefoundation.org.uk/blog/we-mustnt-silence-patientsand-families-in-service-design/

15 Palmer C. Oral evidence to Health and Social Care Committee: Delivering Core NHS and Care Services during the Pandemic and Beyond (Q32). 20201 May https://committees.parliament.uk/oralevidence/331/html/

16 Folkard A, Mann E, Denniston A, et al. No going back: how patients and professionals are exploring the future of eye services beyond covid-19. BMJ Opinion, 5 May 2020.

https://blogs.bmj.com/bmj/2020/05/05/no-going-back-how-patients-and-professionals-are-exploring-the-future-of-eye-services-beyond-covid-19/
17 Hanley B, Tarpey M. Involving the public in covid-19 research. Health Research Authority, 2020. https://www.hra.nhs.uk/about-us/news-updates/involving-public-covid-19-research-guest-blogbec-hanley-and-maryrose-tarpey/

18 Montgomery CM, Chisholm A, Parkin S, Locock L. Wild data: how front-line hospital staff make sense of patients' experiences. Sociol Health Illn 2020.

doi: 10.1111/1467-9566.13115 pmid: 32474965

19 Ocloo J. Being heard, not, "seldom heard": democratising research with diverse communities during the covid-19 pandemic. BMJ Opinion, 2 Jun 2020.

https://blogs.bmj.com/bmi/2020/06/02/being-heard-not-seldom-heard-democratising-researchwith-diverse-communities-during-the-covid-19-pandemic

20 Centre of Excellence on Partnership with Patients and the Public (CEPPP).https://ceppp.ca/en/

21 Inhealth Associates. Learning and development. https://www.inhealthassociates.co.uk/services/learning-development/

22 European Patient Ambassador Programme. https://www.europeanlung.org/en/projects-and-research/projects/european-patient-ambassador-programme-(epap)/home

23 Boivin A, Rouly G. Community initiative co-led with patients could improve care for people with complex health and social needs. BMJ Opinion, 28 Feb 2020.

https://blogs.bmj.com/bmj/2020/02/28/community-initiative-co-led-with-patients-could-improvecare-for-people-with-complex-health-and-social-needs/

24 Canadian Foundation for Healthcare Improvement. Much more than just a visitor: an executive summary of policies in Canadian acute care hospitals. 2020 https://www.cfhi-fcass.ca/docs/defaultsource/itr/tools-and-resources/better_together_executive-summary_en.pdf

25 Stolzoff N. Patient centricity and the covid pandemic. A conversation with Victor Montori [video], 7 Jun 2020. https://www.youtube.com/watch?v=OlJKjhnBdgs

26 Dijk SW, Duijzer E, Wienold M. The role of active patient involvement in undergraduate medical education: a systematic review. BMJ Open forthcoming.

27 Coproduction of research. Nature special issue 3 Oct 2018. vol 362. https://www. nature.com/collections/nnqkvntryl

This article is made freely available for use in accordance with BMJ's website terms and conditions for the duration of the covid-19 pandemic or until otherwise determined by BMJ. You may use, download and print the article for any lawful, non-commercial purpose (including text and data mining) provided that all copyright notices and trade marks are retained. 